\title{
A Study of Relationship between Tourism Logistics and Domestics Self-driving Tour
}

\author{
Dong Kai-ling \\ ${ }^{1}$ Department of Transportation, Chengdu Vocational \& Technical College of Industry industry Career \\ Technical College Chengdu, Sichuan, China

\begin{abstract}
Self-driving tour, which has become the new highlight in tourism market, has great market potential. As one of the parts of tourism, self-driving tour surely includes eating, living, traveling, visiting, purchasing and recreation, and connects with tourism logistics. This article discusses the connection between tourism logistics and self-driving tour and puts forwards some proposals for the development of domestic self-driving tours.
\end{abstract}

Keywords: Tourism Logistics; Self-driving tour; Tourism

\section{INTRODUCTION}

With the fast development of economy and rising of the level of living, travel has become the essential entertainment for people. Self-driving tour also attracts people increasingly. According to the 2015 China self-driving tour development report shows: in 2014 the number of self driving trips about 2 billion 200 million passengers, representing an increase of $8 \%$ over the previous year, accounting for $61 \%$ of the number of annual trips. Self-driving tour, which has become new highlights in tourism market, has a great market in the future. As one of the parts of tourism, self-driving tour surely includes eating, living, traveling, visiting, buying, recreation, and connects with tourism logistics. This article discusses the connection between tourism logistics and self-driving tour and puts forward some proposals for the development of domestic self-driving tour.

\section{LITERATURE REVIEW}

Prideaux (2001): compared with the general tourism, self-driving tour is a collection consisting of a number of tourist destinations, which is not depends only on the individual tourist destination. Therefore, self-driving tour includes roads, road facilities, accommodation, information, tourism and traffic regulations etc.Spotts (1997) think: if people understand the self-driving tourism market, it will be found that there is no fundamental difference between self-driving tourism and ordinary tourism.

Lai Bin (2006): Tourism logistics refers to the tourism activities at the type of material flow, including tourists' belongings and tourism commodity purchase and sale. Wu Zhen(2014): Building a professional tourism logistics information platform, establishment a new type of tourism logistics distribution center, construct of three-dimensional tourism logistics system and integrated optimization of tourism logistics resource allocation.

\section{Methodology}

This paper is on the basis of collecting large number of data, using data analysis, data processing, and on the basis of the field survey.

\section{ReSUlts AND Discussions}

\subsection{Self-driving Tours and Tourism Logistics}

\subsubsection{Self-driving Tour}

Self-driving tour is a form of travel, which originated in the developed countries of Europe and the United States. Initially, driving out at weekend is named as "Sunday-drive", later, it turned into "Drive Travel" .In China, self-driving tourism means momentary experience for person to seek entertainment in different places by self-driving. It has such characteristics as flexibility, experience and variation. 
In China, with constantly rising of people's living standard and traveling demand, self-driving tourism develops quickly in tourism.

\subsubsection{Tourism Logistics}

Many scholars have discussed the conception of tourism logistics in recent years. It has generalized and narrow conception comprehensively. The narrow sense denotes the visible material flow in tourism activities, including the flow of visitors' personal goods and travel merchandise caused by purchasing and selling. Generalized sense denotes all phenomenon and relationship that are concerned with material flow caused by tourism, including transportation, goods care, goods package, goods handling and goods carrying, serve product circulation, information processing and handling This viewpoint focus on the conception of consumer-satisfaction-center and the materials flow for openness, process and certain invisibleness, and offers better understanding about tourism logistics.

\subsubsection{The Connection of self-driving Tours and Tourism Logistics}

Tourism logistics has close connection with travel agencies, shopping enterprises, travel transportation enterprises, travel accommodation enterprises etc. and they affect each other. As a form of traveling, self-driving tour surely include these six factors such as eating, living, traveling, visiting, purchasing and recreation, each factor is related with travel enterprises, which is the basic point of the relationship between self-driving tour and tourism logistics. Tourism logistics includes the flow of visitors, personal goods, and the traffic tool belongs to them which acts as traffic and loading tools, It also includes the rest and sleep tool for tourists in certain necessary situation, that flows among various scenes according the need of its host. So, the self-drive vehicle belongs to the scope of tourism logistics from this point. Therefore, the care and maintenance of vehicle and the supply of self-driving tours' merchandise supply, self-driving tours' traffic as well as the cost problem etc. are the important contents of tourism logistics during the tourism activities.

\subsection{The Problem of Self-driving Tour in China}

\subsubsection{The lagging of Emergency Service in Tourism Logistics for Self-driving Tour}

In China, $66 \%$ of self-driving tourists' traveling distance is within $300 \mathrm{~km}$ one-way. $14 \%$ of selfdriving tourists' traveling distance is $300-500 \mathrm{~km}$ round trip, only $20 \%$ of self-driving tourists' traveling is long distance (see table 1). Most of self-driving tourists' traveling distance is not long, the development of self-driveling tours is not mature, many self-driving tourists do not have the related knowledge on travel safety and the road's traffic condition, All of these factors may possibly cause some accidents and traffic block and influence tour quality, even cause safety problems. However, the emergency service facility to this problem is not perfect, it cannot solve the problems that self-driving tourists meet in time. This causes obstruction on the development of self-driving tours.

Table1. Self-driving tourism distance questionnaire

\begin{tabular}{|c|c|}
\hline Tour distance & The percentage taken \\
\hline $100 \mathrm{~km}$ Within & $18 \%$ \\
$100 \sim 200 \mathrm{~km}$ & $25 \%$ \\
$200 \sim 300 \mathrm{~km}$ & $23 \%$ \\
$300 \sim 500 \mathrm{~km}$ & $14 \%$ \\
$500 \mathrm{~km}$ Above & $20 \%$ \\
\hline
\end{tabular}

Data sources: Chen Qiankang, Research on the Development of Self-driving Tourism Market.

\subsubsection{Neglecting Personal Demand of Travel Merchandise for Self-driving Tourists}

Generally, most of self-driving tourists are youth that have high income and high educational degree, they possessing better life condition, strong travel consciousness and travel attainment. These people often belong to high spending tourism consumer (see table 2). They purchase local characteristic snack, souvenirs as well as the traveling merchandise with national flirtatious expressions in the tour destination. They need various kinds of tourism products with high quality. But now, domestic travel enterprises only tend to meet satisfied common demands, and do not pay attention to the special requirement of travel merchandise for self-driving tourists, and do not offer corresponding products. This is a big defect of self-driving tours in China. 
Table2. Self-driving tourists' consumer conditions

\begin{tabular}{|c|c|}
\hline consumption per person per day & The percentage taken \\
\hline 100Yuan of the following & $27 \%$ \\
$100 \sim 200$ Yuan & $32 \%$ \\
200 300Yuan & $21 \%$ \\
$300 \sim 400$ Yuan & $9 \%$ \\
$400 \sim 500$ Yuan & $6 \%$ \\
More than 500 yuan & $5 \%$ \\
\hline
\end{tabular}

Data sources: Hong Juan,China's Self-driving Tourism Market's Development Power, Feature and Its effect.

\subsubsection{Insufficient Supplying of Invisible Tourism Product}

Travel product is invisible, which makes tourism logistics have its characteristics and differentiate from traditional logistics. Herein tourism logistics not only include the travel line, accommodation information and reservation system service the enterprises should offered, they also should offer some information about destination (including the basic general situation about destination, the characteristic local products and local hotel information etc.). Many travel enterprises do not want to invest and develop the travel line product of self-driving tour because of the high consumption cost. These factors defect the development of self-driving tour.

\subsubsection{Insufficient of Subsidiary Infrastructure for Self-driving Tours}

Most self-driving tourists need map and traffic identification to lead the way until they reach travel destination. The basic of infrastructure in our country is incomplete now, self-driving tourists in the tourism process got complicated, money spend on oil fees and tolls, which caused the tourism cost to be improved. Additionally, if the self-driving tourists have no accurate road information, Tourism commodities may can't be supplied in time.

To a certain extent, it will result in a decrease in the quality of tourism and the tourist satisfaction of tourist destination.

\subsection{Countermeasures of Promoting Self-driving Tour by Tourism Logistics}

\subsubsection{Cooperation between Travel Enterprises and Automobile Companies}

Related travel enterprises should make ample preparation for the problems about the backward emergency service. They can cooperate with rent vehicle companies and automobile clubs. They should get the information of self-driving tourists quickly, offering automobile transport, repair service and protect service for the self-driving tourists who are in trouble. If necessary, these travel enterprises can also connect with local travel accommodation enterprises to offer the overall services such as accommodation and food for self-driving tourists who have problems. These measures resolve the problems that vehicle tourists may meet. On the other hand, these can promote travel destination's image and get acknowledge of self-driving tourists about travel destination and tourism deeply.

\subsubsection{Satisfying the Special Requirement of Self-driving Tourists by Cooperation of Travel Enterprises}

In order to satisfy self-driving tourists' special requirement, travel purchasing enterprises and travel transportation enterprises must know what kind of merchandise self-driving tourists need and then transport them to the scenic spot in time. Especially during the peak of travel time, every travel enterprise and travel destination must cooperate with each other intimately to ensure the supply of tourist commodities and make travel logistics more efficient and cheaper. Besides, every travel destination should keep in touch with each other, and understand the changes about self-driving tourists and renew travel merchandise in time to serve self-driving tourists better.

\subsubsection{Delivering the Information to Self-driving Tourists in Time}

Travel enterprises should realize current situation and transfer the information about products, especially new products to self-driving tourists through various mediums. These measures would not only stress the highlights of travel destinations, but also cater to self-driving tourists' psychological characteristic of hunting for personality, so that travel motivation can be aroused and there would be more tourists. What's more, it can make self-driving tourists get information about destination before their travel. If there is any question, they can feedback to travel destination timely. And then, travel 
destination should know the demand of tourists to offer corresponding service to them. To reduce the cost, travel enterprises should know series of demands of self-driving tourists. Such as distance and cost during the travel, then they can offer special service according to the tourists and popularize it.

\subsubsection{Using GPS and GIS to Manage Tourism Logistics}

Systems can help travel enterprises greatly to manage tourism logistics dynamically. During the traveling peak-hour, travel merchandise must be transported travel destination in time. GPS can be extensively applied in tourism logistics to select optimum line which can greatly avoid sending lately or wrongly. And self-driving vehicles can also select road through these systems, and obtain accurate road information through electronic map in order to avoid going wrong direction. Now there have been some scene spots that have put GPS system into practice. For example, mountain Emei has integrated IT System by using electronic map. The related information owned by scene spot can be detected in the supervising system. Through the grab racket camera, the electronic eye, and the GPS system installed on the buses that spread in scene spot, 95\% of vehicle distribution information is grasped. Besides, through integrated IT System, the self-driving vehicle can be controlled in time. The reasonable distribution and the smooth transfer of tourists in the scene spot come true. And it can prevent the vehicles crowded to cause safety problems, and guarantee the high quality travel experience of self-driving tour.

\section{Conclusion}

With the fast development of various industries and improvement of people's living standard in China, automobile enters Chinese daily life gradually, and become the major acting-step tool for people. According to a statistic, $7.6 \%$ of families will have vehicles, and there will be 14 million personal vehicles in our country, the number of persons who possess driving license will up to as high as 40 million in 5 years. Thus, the people who have vehicle and the potential vehicle buyers will hold a huge self-driving tour market. Self-driving tour in China has become people's one of main stream of outdoor leisure sport, which will spur on the fast development of Chinese tourism industry.

Now, self-driving tour's service field still belongs to traditional travel service pattern in China. The development of self-driving tour still exist a lot of obstructions. In the process of self-driving tour development, putting emphasis on the coordination and the promotion between tourism logistics and self-driving tour can guide the direction and the tendency of competitive tourism market and open a new channel for the healthy development of tourism industry in our country.

Note: This paper is one of the research results of the Sichuan Provincial Department of Tourism Economic Management and Exhibition Innovation team, number: 16TD0037

\section{REFERENCES}

Zhang Xuemei (2011). Research on Self-driving Tourism Traffic Behavior [D].Chengdu: Southwest Jiao Tong University.

Lai Bin, Yang Lijuan (2006). Tourism Logistics: The Perplex and Analysis from Theory to Practice [J].Guang xi social science, 3:62-64.

Liu Dehui (2002).GIS Technical Application in Tourism Industry :Talk about Travel Geography Information System and Its Research Development and Prospect [J].Survey the Information Alternating Paper Fair of Science and Technology,12: 90-95.

Li Li (2005).The Method and the Influence of Self-driving Tour for Current Travel Supply System [J].Coastal Enterprise with Science and Technology,7:166-167.

Liu Jinmin, Li Qianqian. Talking about Self-driving Tours Shallowly[J]. Modern Business, 8:247-248

Yang Jin, Chen Yanhui (2005). The Management of Logistics under E-business and GIS [M]. 59-61.

Yang Zi (2007).How to Panning Tourism Logistics[N]. The Modern Newspaper of Logistics.

Chen Qian-kang (2004). Research on the Development of Self-driving Tourism Market [J]. Tourism Tribune,5:(66-71.

\section{AUTHOR'S BIOGRAPHY}

Dong Kai-ling (1989- ), male, assistant, master. Main research direction: transportation planning. Published 10 papers, participating in 12 research projects, and participate in the preparation of 2 works. 